\title{
Telephone Number
}

National Cancer Institute

\section{Source}

National Cancer Institute. Telephone Number. NCI Thesaurus. Code C40978.

A sequence of decimal digits (0-9) that is used for identifying a destination telephone line or other device in a telephone network. 